\title{
Para una antropología de los sueños humildes. Elementos para trascender el presente etnográfico
}

\author{
For an anthropology of humble dreams. Elements to transcend \\ the ethnographic present
}

Enviado em: 30/09/2020

Aceito em: 05/01/2021

Raúl H. Contreras Román ${ }^{1}$

A una promesa que afecta tanto al presente y al pasado tanto como al futuro mejor la llamariamos certeza Jonh Berger

\begin{abstract}
Resumen
En la literatura socioantropológica sobre el cambio social ligado a la migración de poblaciones indígenas mexicanas, primero campo-ciudad y luego internacional, se percibe una especie de zona gris, en que la linealidad del proceso parece desacoplarse. En particular me refiero a las narrativas contrastantes que en un polo tienen al indígena atávico y apático al cambio, presentado por las etnografías indigenistas del siglo pasado; $y$, en el otro, al indígena que en las antropologías contemporáneas aparece como apetente de la novedad, el consumo, la superación de la pobreza, la mejora educativa y todo lo involucrado en la búsqueda del bienestar. En este artículo propongo que una alternativa para indagar en esa zona gris es prestar atención a los sustratos temporales implicados en dichos cambios, a las formas en que las comunidades indígenas logran articular desigual y discontinuamente lo viejo y lo nuevo en la construcción de sus contemporaneidades $y$, sobre todo, a las múltiples maneras en que la búsqueda de formas de ganarse la vida vinculadas a la constante movilidad, fueron despertando aspiraciones y sueños humildes entre los trabajadores migrantes y sus comunidades que, comprometidos con esas imágenes de futuro, prefiguraron y prefiguran el porvenir en su práctica presente.
\end{abstract}

Palabras-clave: Futuro; Antropología; Sueños humildes; Migración.

1 - Es doctor en antropología, investigador del Centro de Investigaciones Interdisciplinarias en Ciencias y Humanidades, de la Universidad Nacional Autónoma de México (CEIICH-UNAM). Sus campos de interés son la antropología del tiempo —en particular las orientaciones de futuro-, la antropología económica, los estudios rurales y campesinos. En estos campos ha publicado diversos artículos y capítulos de libros.

Revista Memória em Rede, Pelotas, v.13, n.24, Jan/Jul.2021 - ISSN- 2177-4129

periodicos.ufpel.edu.br/ojs2/index.php/Memoria 


\begin{abstract}
In the socio-anthropological literature on the social change linked to the migration of Mexican indigenous populations, first country-city and then international, a kind of gray area is perceived, in which the linearity of the process seems to be decoupled. In particular, I refer to the contrasting narratives that at one pole have the indigenous atavistic and apathetic to change, presented by the indigenous ethnographies of the last century; and, on the other, the indigenous person who in contemporary anthropologies appears as appealing to novelty, consumption, overcoming poverty, educational improvement and everything involved in the search for well-being. In this paper, I propose that an alternative to investigate this gray area is to pay attention to the temporal substrates involved in said changes, to the ways in which indigenous communities manage to articulate the old and the new unevenly and discontinuously in the construction of their contemporaneities and, above all, to the multiple ways in which the search for ways to earn a living linked to constant mobility, were awakening humble aspirations and dreams among migrant workers and their communities that, committed to these images of the future, foreshadowed and foreshadowed the to come in your present practice.
\end{abstract}

Keywords: Future; Anthropology; Humble dreams; Migration.

\title{
Introducción
}

Tras los grandes temas que concentran las discusiones contemporáneas sobre el fenómeno migratorio entre México y Estados Unidos, como la tasa de migración cero, suele obliterarse que, tanto a nivel macroeconómico, como a nivel de amplias economías regionales, sobre todo rurales, la migración sigue constituyendo una dinámica fundamental, porque los que están "al otro lado", como migrantes casi siempre indocumentados, continúan haciendo de su esfuerzo un compromiso con los suyos y con su terruño. De este modo, a través de la migración se continúan hilvanando sueños humildes: los de aquellos que quieren construir un futuro a mano, donde las manos de los que cruzaron "al otro lado" a ofrecerse como mano de obra barata, han sido fundamentales. Esos sueños, son los de un mejor pasar, de formas locales de pensar el bienestar, de construir la vida buena $y$, antes, mucho antes que eso, de hacer la vida posible en espacios donde por décadas ello parecía negado.

Si la historia reciente de México puede entenderse considerando la dinámica migratoria, esa historia puede contarse también en narrativas locales que tienen como puntos nodales las experiencias de personas que mediante la migración han intentado concretar sus sueños y aspiraciones para hacer posible, por medio de la experiencia

Revista Memória em Rede, Pelotas, v.13, n.24, Jan/Jul.2021 - ISSN- 2177-4129 
misma de la pesadilla americana, un sueño mexicano coronado por el deseo de un futuro retorno. Son esos sueños humildes los que otorgan sentido temporal a las narrativas locales del cambio social en muchas comunidades campesinas e indígenas de México.

En este artículo indagaré en una de esas narrativas locales que cuentan el cambio social desde abajo, a partir de las aspiraciones y los sueños humildes de personas de una comunidad indígena del centro de México que, en la movilidad laboral —primero campociudad y luego internacional-, descubrieron formas novedosas de articular sus presentes de esfuerzos a sus maneras de imaginar el futuro. Con base en dicha exploración, hacia el final del artículo, sugiero algunos elementos teórico-metodológicos para una antropología del futuro que, atenta a los sueños humildes, logre trascender el presente etnográfico.

\section{El imperativo de la movilidad}

La historia reciente de El Boxo, una comunidad otomí hñahñu² de poco más de 210 habitantes, localizada en el Valle del Mezquital, en el centro de México, puede trazarse siguiendo la línea de los sueños humildes de sus habitantes que, buscando la forma de ganarse la vida, descubrieron también formas de ir articulando el presente a futuros deseados. Si se escucha con atención a los señores y las señoras mayores de la comunidad, se distinguirá que la eclosión de esos sueños se remonta varias décadas antes de que la migración transnacional se hiciera norma a finales del siglo pasado.

Como sucedió en otras tantas comunidades indígenas dispersas en el territorio alto del Mezquital, los habitantes de El Boxo tuvieron una relación marginal con los principales polos capitalistas y mercantiles -la minería y la hacienda- que desde la Colonia, se desarrollaron en la región. Por ello, los medios de vida se resolvieron en los marcos de una economía tradicional relativamente autárquica. Esta autarquía lejos de estar basada en la autosuficiencia, estuvo dada por un precario equilibrio entre producción campesina y consumo que, según expresan en sus evocaciones las personas mayores de la comunidad, redundaba en fuertes carencias en el ámbito de la alimentación. Dicha

2 - A lo largo de este artículo haré referencia indistinta a lo otomí y lo hñahñu para referirme a los habitantes del Valle del Mezquital, su lengua y autoadscripciónidentitaria.

Revista Memória em Rede, Pelotas, v.13, n.24, Jan/Jul.2021 - ISSN- 2177-4129

periodicos.ufpel.edu.br/ojs2/index.php/Memoria 
situación empezó a mudar cuando, desde mediados del siglo XX, los habitantes de la comunidad comenzaron a migrar estacionalmente a la capital del país, para emplearse como albañiles y trabajadores en el sector de la construcción en una ciudad que crecía impulsada por los bríos del Milagro Mexicano.

Los primeros trabajadores que salieron de la comunidad en busca de dinero, retornaron a ésta con ahorros, nuevos consumos, nuevas aspiraciones. El cemento que en la ciudad hizo surcos en sus manos, donde antes sólo hacía surco la coa campesina, vino también con ellos para construir nuevas formas de habitar la comunidad. El dinero se transformó en el eslabón que unió la necesidad presente con las aspiraciones de tiempos venideros. Desde entonces el dinero buscó otros dineros y los trabajadores otras variadas ocupaciones. El futuro que descubrieron aquellos primeros trabajadores migrantes a Ciudad de México, ulteriormente se encontró con el de generaciones que aprendieron a improvisar trayectorias y formas de ganarse la vida y que hicieron del andar trabajando fuera, un habitus.

A primera vista puede parecer extraño situar a mediados del siglo pasado la apertura al tiempo porvenir de los habitantes de El Boxo y ligar sus prácticas para ganarse la vida al descubrimiento de novedosas formas de imaginar la vida buena. Cualquier lector informado de las discusiones de la antropología mexicana del siglo XX, sabrá que el Valle del Mezquital fue tempranamente instaurado como la región arquetípica de la pobreza y el rezago sociocultural de los indígenas del país. Sin ir más lejos, basta recordar que, por esos mismos años, el padre de la antropología mexicana, Manuel Gamio, reconoció al Mezquital como "el rincón de mayor pobreza e incultura de la República," donde "milenarios sistemas," persistían "contra toda enseñanza" y donde muchas de "las anacrónicas sobrevivencias del Otomi" eran "retardatarias y perjudiciales" (GAMIO, 1952:218-223). Dos décadas después, cuando el Valle se transformó en el laboratorio de las discusiones entre indigenistas y marxistas, un amplio estudio desarrollado en la región no demoraba en concluir que "una cultura secularmente oprimida como la otomí, que ha vivido en la inseguridad permanente, pasiva y necesariamente defensiva, es una cultura cuyas capacidades autopropulsoras están aletargadas, una cultura enajenada que no se proyecta al futuro" (COPEVI, 1970: 115).

En mi exploración (CONTRERAS, 2019) he procurado demostrar que tras esa imagen de un otomí atávico y apático al cambio, se esconde la historia local de 
generaciones que hicieron suyo el deber de levantar sus comunidades a través de la migración, vinculando los esfuerzos del andar lejos con el compromiso con aquellos cercanos que se quedaban. Son aquellas generaciones a las que, un etnógrafo local como Raúl Guerrero (1983: 219), les asignó "un nuevo espíritu de elevación material” y a las que, el maestro Hermenegildo, de la primaria de El Boxo, describe como las que iniciaron el "contagio" hacia el "tener un poquito más de economía". Son esas generaciones las que, para bien o para mal, inauguraron la secuencia de transformaciones que hoy configuran los paisajes etnográficos del Valle del Mezquital.

Dentro de los múltiples aprendizajes sociales que la experiencia de movilidad laboral aportó a los trabajadores de El Boxo, quizá la fundamental fue la del imperativo del andar trabajando lejos para hacer posible la vida en la comunidad. Tras ello, observo la emergencia de una especie de solidaridad sobre la que se sustentó la reproducción social y, al mismo tiempo, se impulsó la transformación radical en los modos tradicionales de entender el bienestar, la escasez, la dignidad y, todo aquello que la antropología vinculó a la idea de modos de vida y que tempranamente Robert Redfield ([1953] 1963) relacionó con la noción de vida buena.

Dicha solidaridad se afincaba, en primer término, en los modos en que el esfuerzo presente del que andaba lejos trabajando se engarzaba con la reproducción de la vida de los suyos que se quedaban en la comunidad. Este vínculo no demoró en incorporar aprendizajes temporales que se correspondieron de manera directa con la temporalidad del dinero. El futuro, bajo nociones de ahorro, encerró nuevas maneras de aspiración, de imaginación de lo venidero vinculada a formas emergentes de pensar la vida buena. De este modo, el esfuerzo de los que andaban lejos y de quienes se quedaban en la comunidad se engarzaba en proyectos comunes, en sueños comunes, por concretar esas imágenes. La incipiente modificación del patrón constructivo de las viviendas del Mezquital comenzó a ser expresión material de dicha concreción.

No se equivocaba el antropólogo Luigi Tranfo ([1974] 1990) en decir, a comienzos de los años setenta, que los bloques de cemento apilados fuera de humildes chozas otomíes eran historias de dolorosos ahorros. Desde luego lo eran. Pero asimismo, eran evidencia de un cambio fundamental en los modos de entender el bienestar y, más ampliamente, la vida buena; que rompían o, por lo menos desestabilizaban, pautas tradicionales como las que Jacques Galinier (1977), por esos mismos años, había 
caracterizado como un modelo de pobreza y respeto a la tradición, presentes — según el antropólogo francés - en las formas de construir la vivienda otomí vernácula. ${ }^{3}$ Pero al mismo tiempo, esos bloques de cemento que esperaban ser algún día una casa, eran evidencia de una particular manera de engarzar el presente al futuro y, con ello, dotar de una trama temporal a los sentidos de pertenencia.

Desde mediados del siglo $\mathrm{XX}$, en su zigzaguear entre el campo y la ciudad, los trabajadores de El Boxo descubrieron en la construcción de la casa una posibilidad de articular los presentes de esfuerzos a los futuros imaginados de vida buena. Una forma sutil de enfrentar el desarraigo. En su investigación sobre jornalerismo agrícola en el Valle del Mezquital de mediados de la década de 1970, HubertCarton (1982: 87-8) escribía:

\begin{abstract}
Es increíble constatar como el hecho de tener un solar y una casita donde vivir, por muy pobre que sea, es determinante para impedir que un peón se vaya [...] que migre definitivamente. Claro está que frente a la necesidad se da la migración del campo a la ciudad, pero queremos destacar que en las condiciones de pobreza de los peones y frente a la dificultad de encontrar un trabajo seguro en la ciudad, el solar y la casita representan la única seguridad de la cual no se desprende fácilmente el peón.
\end{abstract}

Desde entonces, junto al difícil presente y sus múltiples urgencias, lo que dotó de sentido e hizo significativas las diversas prácticas de los habitantes de El Boxo para ganarse y hacer posible la vida en la comunidad, fue ubicar dichas prácticas en el marco imaginario y proyectivo de la vida buena. Ésta tuvo su referente material en cambios significativos en las condiciones de vida, manifiesto por ejemplo en la edificación de casas de concreto o en la llegada de la energía eléctrica, que los habitantes de la comunidad comenzaron a experimentar junto a la migración laboral a Ciudad de México. En esos cambios la colaboración económica de quienes andaban lejos trabajando fue fundamental. Cada uno de estos avances fueron colocados como fragmentos de

3 - Diversas etnografías de las décadas del cincuenta, sesenta y setenta del siglo pasado registraron la progresiva transformación de las viviendas en nuestra región, desde aquella vernácula construida con maguey, el encino, palma, carrizo, barro, piedra, tepetate, tzaquiá o mezquite; a aquella construida predominantemente con bloques de cemento y variaciones industriales (zinc, asbesto, caucho o cemento) para los techos (Padelford, 1969; Tranfo, [1974] 1990; Medina y Quezada, 1975; Ramsay, 1974, Nolasco, 1963; Guerrero, 1983; Galinier, 1977). Lo que para algunos era resultado de un proceso de aculturación incentivada por la migración, para otros era evidencia de la creciente diferenciación social. En esta transformación un rol importante lo ocupó el Estado mexicano que vía instituciones de intermediación como el Patrimonio Indígena del Valle del Mezquital (PIVM), promovió el abastecimiento de materiales modernos para estandarizar las formas de construcción de las casas. Sin embargo, el influjo principal en la transformación de las viviendas devino de la migración laboral estacional a Ciudad de México.

Revista Memória em Rede, Pelotas, v.13, n.24, Jan/Jul.2021 - ISSN- 2177-4129

periodicos.ufpel.edu.br/ojs2/index.php/Memoria 
esperanza en la articulación entre el presente de esfuerzo y el futuro imaginado, entre los sueños humildes y sus pequeñas concreciones.

Así la construcción de la totalidad imaginaria de la comunidad, se apoyó en el desarrollo de narrativas en que las líneas del pasado, fueron imaginariamente articuladas con aquellas dedicadas a esbozar futuros, elaborados a partir de proyectos individuales, familiares y comunitarios para mejorar la vida en la comunidad, aunque para ello los tiempos y las distancias de las ausencias fueran cada vez mayores.

Sostener ese compromiso en el tiempo, requirió de prácticas concretas y novedosas en las formas de organización social. La ausencia cuasi permanente de parte de los miembros de la comunidad que salían tras un salario, a distancias y periodos de tiempo cada vez mayores, demandó el esfuerzo comunitario por construir prácticas sociales que vincularan el esfuerzo de la salida y el andar lejos con la realidad de quienes se quedaban. Esto es lo que puede denominarse gestión de la ausencia, idea bajo la cual intento conceptualizar al conjunto de arreglos prácticos, así como de sus narrativas, que -no sin conflicto- posibilitaron y posibilitan que aquellos que andan trabajando lejos mantengan una presencia en ausencia en la comunidad, tanto a nivel afectivo como material.

El sustrato de esas prácticas, que ha permitido su duración en el tiempo, fue el temprano vínculo temporal que los habitantes de la comunidad establecieron entre el presente de esfuerzo (del andar trabajando lejos) y el futuro conceptualizado bajo nociones situadas de vida buena. Participar en las mejoras de la comunidad como forma de garantizar mejores condiciones de existencia para la familia, se convirtió para los migrantes en una forma de asegurar su lugar para el retorno a la comunidad. Pertenencia, compromiso con quienes se quedaban y gestión de la ausencia se vincularon desde entonces al imperativo de la movilidad laboral.

Por esto no es trivial que en las evocaciones de aquellos que comenzaron a migrar a Estados Unidos en las décadas finales del siglo XX, aparezcan en un mismo plano las descripciones de aquel presente pasado de la urgencia (migrar: "porque acá ya no hubo [trabajo]") con la intención de futuro imaginado que, en aquel presente, les hizo actuar ante la clausura de sus medios de vida ligados a la movilidad estacional a Ciudad de México. Migrar "para tener un futuro mejor" o, más radicalmente, para optar a un futuro con futuro, significaba mantener el compromiso simbólico con sueños humildes ya trazados, con las imágenes situadas de porvenir y de vida buena, más allá del impasse de 
la crisis, el agudo presente y el colapso económico mexicano de la época. En este punto, es necesario recordar que la migración emerge tanto como "un símbolo y una representación de la esperanza y de la fe en el futuro y, al mismo tiempo, como un acto o una reacción a la desesperanza, la desesperación y la pérdida aguda del presente" (Pine, 2014: 96).

\section{Pertenecer desde lejos}

Tras aquella gestión de la ausencia, se hilvanan los sentidos íntimos y públicos bajo los cuales se define, se ejerce y se reclama la pertenencia contemporánea de los migrantes en Estados Unidos a la comunidad de El Boxo. Un modo de pertenecer que es posible de definir bajo la noción de pertenencia ontológica, propuesta por la socióloga Julia Bennett (2012), para quien pertenecer ontológicamente es estar implicados, en tiempo presente, en un conjunto de obligaciones mutuas para cuidar el pasado y el futuro de los lugares y de quienes los habitan.

En comunidades indígenas hñahñu como El Boxo, la pertenencia y la ciudadanía, no constituyen una condición per se. Desde luego las afiliaciones étnicas e identitarias forman parte de las nociones locales de pertenencia y ciudadanía; no obstante, ambos conceptos se relacionan con mayor intensidad con la idea de convertirse en una persona plena, a través del cumplimiento continuo de las obligaciones que se adquiere en relación con los demás miembros de la comunidad. Ser ciudadano de la comunidad es estar implicado en ésta a través de una serie de compromisos y obligaciones de los que resultan también derechos. ${ }^{4}$

Para los migrantes cuidar las formas de pertenencia es de alguna manera cuidar la condición de ser en el lugar. Seguir siendo, aún estando lejos, es trabajar en el presente por no perder esa condición de pertenencia que asegure el retorno futuro. Pero andar

\footnotetext{
4 - "La ciudadanía comunal de los indígenas hñähñu del Valle del Mezquital es un tipo de ciudadanía negociada afuera de las definiciones normativas de ciudadanía y por debajo de los niveles de gobernabilidad del Estado-nación. En este caso, está íntimamente ligada a expectativas de carácter cívico que definen la membresía (pertenencia) comunal. Esta ciudadanía es de tipo activo y resultado de prácticas sociales diarias a través de la participación cívica: los hñähñu alcanzan y exigen su ciudadanía comunal a través de la participación en faenas y cargos (en su mayoría civiles) que benefician a la comunidad en pleno [...] La ciudadanía comunal es, entonces, un producto de un proceso continuo de negociaciones culturales, sociales y económicas, tanto internas como externas [...]. Es igualmente el cimiento de la identidad y el sentido depertenencia (membresía) comunal. El ser migrante y estar ausente de los quehaceres y decisiones diarios de la comunidad no lo eximena uno de sus obligaciones ciudadanas." (Schmidt, 2013: 148-9).
}

Revista Memória em Rede, Pelotas, v.13, n.24, Jan/Jul.2021 - ISSN- 2177-4129

periodicos.ufpel.edu.br/ojs2/index.php/Memoria 
trabajando lejos es también, como ya he dicho, la forma específica que los habitantes de El Boxo descubrieron para ganarse y hacer posible la vida en la comunidad, desde que los padres de los hoy migrantes en estados Unidos, comenzaron a migrar temporalmente a Ciudad de México. Un compromiso práctico con el cuidado del lugar, del cual emergen nociones de pertenencia a éste.

Las contemporáneas discrepancias temporales de la migración (GARDINER; LEM, 2018), referidas a las inconsistencias y las escalas de tiempo disyuntivas en las vidas de los migrantes, en relación con las prioridades temporales de las agendas estatales neoliberales y los ciclos de acumulación de capital, presentan un desafío a las maneras en que se practica la gestión de la ausencia y su vínculo con las pertenencias en El Boxo. Para muchos migrantes mezquitalenses, sus proyectos migratorios parecen temporalmente suspendidos, encerrados entre dos imposibilidades: la de la radicación definitiva en Estados Unidos y la del retorno libre con la posibilidad de volver a migrar. La temporalidad del proyecto migratorio hoy no está en manos de los migrantes y la incertidumbre de futuro parece ser razón para un sacrificio que pierde sentido en el presente.

En este punto, la incertidumbre que no permite al migrante otra existencia por no encontrar estatus o reconocimiento en el lugar de destino, podría resultar en la desidentificación defendida por Michel Agier (2015). Según este antropólogo, la desidentificación se produciría por la pérdida o el alejamiento de los lugares, de los lazos y de los bienes que han constituido la identidad de aquel y aquella que migra en condiciones de extrema carencia. Esa desidentificación, según el autor, parece no poder transformarse en otra existencia porque las personas no logran encontrar lugar, estatus o reconocimiento diferente a su vida simplemente precaria, en el lugar de destino.

A diferencia de lo planteado por Agier (ibíd.), a partir de mi trabajo en El Boxo defiendo que lejos de resultar en una desidentificación, para los migrantes mezquitalenses las actuales discrepancias temporales de la migración, redundan en un reforzamiento de los compromisos con la pertenencia al lugar de origen. Ello es resultado, tanto del mantenimiento de los compromisos morales con la familia y la comunidad, como de la persistencia en un proyecto migratorio y, en éste, la emergencia de una especie de contraste en que el presente precario, de esfuerzo y explotación, se imagina como 
circunstancia puntual para la construcción de un futuro diferente en el lugar al que sí se pertenece.

Se articulan con ello formas novedosas de pertenencias, posibles de vincular a lo que la socióloga VannessaMay $(2017,2017 a)$ describe como el pertenecer desde lejos. Un desplazamiento de los sentidos de pertenencia no sólo en el espacio, sinoque también en el tiempo. Se pertenece a un espacio y un tiempo otro y no al aquí y al ahora, cuando el presente bloquea el desarrollo de las pertenencias. Ese otro tiempo que otorga sentido a la pertenencia es predominantemente el pasado, que según nos dice May, se activa con la memoria o con la nostalgia que emergen como fuente "de continuidad del yo, incluso bajo circunstancias externas cambiantes" (MAY 2017a:412). Pero, de manera similar, pertenecer desde lejos puede estar implicado con las formas creativas en que el futuro se anticipa en las narrativas de la pertenencia a manera de "evitar un presente imperfecto lleno de dilemas y paradojas" (ibíd., 2017: 322).

Los migrantes de El Boxo pertenecen desde lejos no sólo porque en el presente su integración con ciudadanía plena a la sociedad estadounidense, está bloqueada; sino que por sobre todo, porque sus memorias les implican con El Boxo como su lugar de origen, su ahora de esfuerzos les vinculan con el presente de los que se quedaron y su añorado retorno futuro, les liga con el porvenir de la comunidad. Para ello insistir en los sueños humildes, continuar gestionando la ausencia y administrando las esperas, bajo formas diversas y casi siempre afirmativas de pensar lo venidero, es vital.

No por otra cosa la presencia de las obras y de los procesos constructivos es tan ubicua en el Valle del Mezquital. El cemento que se derrama en casas vacías construidas para el futuro retorno de migrantes o en obras públicas tan disímbolas y llenas de metáforas como un monumento al dólar o una cruz gigante, donde quienes se quedan encienden veladoras por la salud de los que andan lejos, hacen del concreto la huella más concreta de la experiencia actual del andar lejos, de la espera y de los instantes que presentifican los futuros imaginados (CONTRERAS, 2019a). El hombre, apuntaba el arquitecto JuhaniPallasmaa (2015:72), es capaz de construir sólo si tiene esperanza. Por ello el cemento y las obras forman parte expresiva de la contemporaneidad del Valle del Mezquital y están profundamente implicadas en las narrativas locales del cambio social y en los fragmentos de esperanzas con los que se sigue edificando la versión mezquitalense de la vida buena.

Revista Memória em Rede, Pelotas, v.13, n.24, Jan/Jul.2021 - ISSN- 2177-4129 


\section{Reafirmar el compromiso}

No estoy seguro si lo anterior pueda representarse sólo como un "optimismo cruel", idea bajo la cual, desde la teoría feminista, se ha criticado a las perspectivas del bienestar (cf. BERLANT, 2012). Lo que sí es claro es que, sin ese vínculo temporal expresado en el compromiso de engarzar el presente de esfuerzo y el futuro de vida buena imaginado, las distancias hubiesen sido insoportables o definitivas. Ello cobra mayor sentido ante las contemporáneas discrepancias temporales de la migración. En esta etapa, en que la incertidumbre y la espera parecen definir la temporalidad del proyecto migratorio, reafirmar el compromiso con la gestión de la ausencia y con la imagen de vida buena como proyecto de futuro situado en el lugar de origen, constituye un mecanismo contra la desidentificación (cf. AGIER, 2015) que propicia formas temporo-espaciales para "pertenecer desde lejos" (MAY, 2017a). Es precisamente ese compromiso el que, en el sentido de AmartyaSen (1977), se intrinca con valores morales que engarzan el presente de esfuerzo del migrante, con su deseo de vida buena para los suyos en la comunidad. Al mismo tiempo que es ese compromiso el que actualiza, en el sentido de SlavojŽižek (2012), la idea de futuro materializándola en la acción comprometida del migrante con dicha idea. En ambos sentidos el compromiso adquiere un valor generativo y prefigurativo que se expresa en las narrativas locales sobre el cambio material de las condiciones de vida en El Boxo.

La profunda y permanente diferenciación entre el tiempo de vida y el tiempo del trabajo que, en otros términos, se dirime también en el tiempo del estar en la comunidad y el estar lejos de ésta, no deja de ser una experiencia trágica para los que andan trabajando lejos y para los que se quedan. Situar esta experiencia en las narrativas locales de la construcción de sueños humildes de cara a un porvenir mejor, en las formas de pertenencia y en el compromiso que se adquiere con los cercanos y con el futuro propio, no es insistir cruelmente en el optimismo de la promesa de futuro como artilugio retórico para acicalar la tragedia de tener que andar lejos de los seres queridos para hacer posible la vida propia y la de éstos. Es, por el contrario, acercarse a los sentidos temporales desde los que se construyen seguridades ontológicas mínimas (cf. GIDDENS,1997) que, además de permitir vivir la tragedia, otorgan valor situado a las prácticas, los discursos y las formas múltiples con las que ésta se experimenta y nombra.

Revista Memória em Rede, Pelotas, v.13, n.24, Jan/Jul.2021 - ISSN- 2177-4129 
Quizá pueda distinguirse, como sugiere Eagleton (2016), esperanza de optimismo y sugerir así que los fragmentos de esperanza, sobre los cuales se han asentado los nodos para continuar atando el presente a un futuro de vida mejor, imaginado en El Boxo, no son ni optimistas ni crueles. Pero para las generaciones que trabajaron a pulso y vieron el cambio producido, como me dijera uno de mis colaboradores, "de volada" en la comunidad, la visión de un pasado económicamente abyecto es contrastante con la contemporánea imagen afirmativa del porvenir, sustentada en los logros de algunas metas que configuraron la imaginación de futuros pasados. Como hemos apuntado en otra parte (VALENCIA; CONTRERAS, 2018: 19) cuando el futuro se mira como legítima aspiración de cambio hacia una vida mejor, la esperanza hace posible la disposición y la capacidad para atreverse en lo todavía no logrado. En aquellos intersticios imaginarios y vitales, la esperanza ayuda a conocer el futuro como (y por medio de la) esperanza.

\section{Imaginar futuros}

La imaginación como activante de la realidad misma, es fundamental para interrogarnos sobre las múltiples maneras en que las imágenes de futuro impactan en el presente y, asimismo, para preguntarnos por las formas en que los futuros pasados se han materializado en el ahora del presente etnográfico. No podemos, decía Marc Augé (2015: 100), "interesarnos por el porvenir sin chocar con la presencia masiva y heteróclita de la imaginación".

El papel de la imaginación nos ayuda a interpretar que el presente material de la comunidad de El Boxo es, en parte, resultado de la imaginación de futuros pasados, en que se configuraron nociones de vida buena que encaminaron prácticas para transformar las formas de construir y habitar la comunidad. Del mismo modo, el papel de la imaginación posibilita adelantar que el futuro de la comunidad será, también en parte, resultado de las prácticas presentes sobre las que los futuros imaginados ejercen un rol en tanto que orientador $\mathrm{y}$, al mismo tiempo, dotante de sentidos a dichas prácticas.

Cuando digo "en parte" intento remarcar la indeterminación temporal que a la vez que no permite hacer lecturas lineales a nivel retrospectivo, impide otorgar una linealidad similar al vínculo presente-futuro. Para una antropología del futuro que procure otorgar al tiempo porvenir una igualdad ontológica respecto al que tradicionalmente en la antropología hemos otorgado al pasado en la configuración del presente, es necesario - 
como ha apuntado FelixRingel (2018) - asumir un cierto grado de contingencia e indeterminación en cualquier parcialidad del tiempo. Con ello se desestabilizan las ideas en torno a la predeterminación temporal y se asume que, en cualquier momento del tiempo, nos enfrentamos a la probable aparición de una variedad de futuros posibles, así como de presentes que reclamen pasados alternativos a los que hasta ese momento eran asumidos como sus prefiguraciones.

La contemporaneidad de El Boxo está plagada de futuros pasados que llegan al presente con texturas y gravitaciones diversas (CONTRERAS, 2019b). Pero del mismo modo, esta contemporaneidad está impregnada de imágenes de futuro que alimentan diversos compromisos en el presente. Volver la vista a los sueños humildes que se tornaron proyectos en el sentido más indispensable del término, posibilita entender que tras las elucubraciones apocalípticas y distópicas que saturan los estudios sociales contemporáneos ( $\mathrm{LYNCH}, 2012)$, se esconden formas discretas de seguir apostando por el tiempo porvenir y con ello seguir construyendo presentes comprometidos con enredos morales y de valor que trascienden las lógicas dominantes.

El cambio en las condiciones materiales de existencia en El Boxo, como en gran parte del Valle del Mezquital, constituye una realidad fáctica que los habitantes reconocen como tal. Dichos cambios son una experiencia del tiempo, que les permite a estos habitantes nombrar los antes y los después de su historia colectiva. El establecimiento de la escuela, la llegada de la electricidad, el trazado de caminos, la apertura de la carretera, su pavimentación, la construcción de las casas de concreto, la edificación de la iglesia, la llegada del transporte público; entre otras cosas, son marcadores en las narraciones con las que los habitantes de El Boxo cuentan su historia. En cada uno de estos marcadores, el vínculo con la movilidad laboral es evidente. Con ello aparecen el esfuerzo y las historias más íntimas. Las transformaciones en la comunidad se asocian con las trayectorias laborales propias, porque se reconoce el influjo de aquellas experiencias individuales en la historia colectiva.

Si la vida buena no es un estado, sino una aspiración continua (FISCHER, 2014; MILLAR, 2018; JACKSON, 2011; APPADURAI, 2015), los esfuerzos materiales por hacer posible la vida están imaginativamente imbricados en el ganarse la vida como acción presente (NAROTZKY; BESNIER, 2014), al mismo tiempo que son dichos esfuerzos presentes los que materializan y, como dijera Redfield (ibíd.: 72), contribuyen a dar forma a las ideas de lo que es la vida buena. En El Boxo, la imagen de futuro que hoy se 
conceptualiza como vida buena, está saturada de los presentes futuros que buscan alcanzarla, así como de los futuros pasados que le fueron conformando. En la articulación de ambas iteraciones temporales, los fragmentos de esperanza, aquellos trozos de sueños concretizados, aparecen como elementos de realidad vivida en el presente y, al mismo tiempo, como conectores narrativos de aspiraciones que presentifican el futuro imaginado y hacen de éste un futuro vivido (cf. ADAM; GROVE, 2007).

\section{Más allá del presente etnográfico}

Al considerar las múltiples iteraciones temporales que vinculan las nociones de vida buena con las formas de ganarse la vida, es posible pensar al pasado, aproximarse al presente e imaginar el futuro de una colectividad social como El Boxo. Pero más allá de aquello, que debiese constituir una exigencia para la investigación antropológica y su construcción del presente etnográfico como tiempo-espacio de lo contemporáneo, considerar las iteraciones temporales señaladas implica asumir el peso que adquiere la imaginación del futuro en la configuración de realidades en cualquier presente.

Esto último ha sido, aun asumiendo la diversidad de enfoques, un punto en que las antropologías del futuro parecen coincidir. Ya el pionero trabajo de Sandra Wallman (1992), en su intento por definir una antropología del futuro, planteó que ésta, lejos de estar interesada en la predicción o en lo que hoy se reconoce como prospectiva, busca indagar en las formas particulares en que el tiempo futuro es imaginado en el presente. Preguntarse por las maneras en que los futuros imaginados y anticipados impactan en el presente (MANKEKAR; GUPTA, 2017), por la relación entre las representaciones del tiempo porvenir y las prácticas posibles (GODINHO, 2017) o por las diversas formas en que la acción presente está configurada por las orientaciones de futuro (BRYANT; KNIGHT, 2019), supone repensar el presente etnográfico y, del mismo modo, examinar las formas en que en la antropología pensamos el futuro como configurador del presente. Si el futuro aparece como un horizonte cultural (APPADURAI, 2015) y el tiempo histórico resulta de la tensión entre los campos de experiencias y los horizontes de expectativas (KOSELLECK, 1993); el pasado que describimos en nuestras etnografías fue también, en su tiempo, el espacio de futuros que llegan a nuestros días como futuros pasados, con texturas y gravitaciones diversas en la configuración del presente. Del mismo modo se expresan las iteraciones temporales del futuro en el tiempo presente. En éste se 
manifiestan futuros pasados conclusos, así como otros inconclusos que siguen siendo horizontes para imaginar presentes futuros y futuros-futuros.

De tal modo, los tiempos del tiempo presente de la etnografía, aparecen entreverados porque las personas viven su actualidad articulando en ella iteraciones temporales múltiples. Nunca se vive ni se habla del todo en tiempo presente, pasado o futuro, porque en una misma frase o idea los tiempos son conjugados o, en otras palabras, como ha apuntado JöelCandau (2002:33), porque "no podemos recordar un hecho pasado sin que el futuro de ese pasado se integre a su recuerdo".

"[Yo] mando a los niños a la escuela, porque quiero que sean más de lo que fui yo", me decía una mañana una habitante de El Boxo para explicarme que el "mejor futuro" de los niños ya no estaría vinculado, como lo estuvo para su generación, al proyecto migratorio. En frases como esas, el presente (del mandar a los niños a estudiar), se expresa al mismo tiempo que el futuro (de la proyección) y el pasado (que emerge como evaluación contrastante de lo que se desea como porvenir).

Algo similar acontece con las prácticas. Ello es lo que he buscado mostrar bajo la noción de formas de ganarse la vida. Ganarse la vida, como han defendido Narotzky y Besnier (2014), es indisociable del esfuerzo material y temporalmente sostenido por reproducir la vida y hacer que la vida valga la pena. La noción de forma de vida que, siguiendo a Kathleen Millar (2018: 9), involucra ideas en torno a los medios de vida, el estilo de vida y la vida buena o, en otros términos, a las formas diversas de habitar, construir y reproducir el mundo; implica una concepción en que el "trabajo se entiende en un sentido amplio, estrechamente relacionado con los valores y las creencias sobre la vida buena y con las luchas humanas para realizar estas visiones incluso dentro de restricciones sociales brutales" (ibíd.: 26).

La experiencia de los trabajadores de El Boxo muestra que existe un vínculo temporal intrínseco (entre pasado, presente y futuro) en las prácticas económicas, aún en aquellas que parecen en extremo defensivas ante la pobreza, la precariedad de los mercados laborales y la persistente ruina de los medios de vida de comunidades rurales e indígenas. Incluso bajo el peso de la urgencia, las formas de ganarse la vida en dichas condiciones implican prácticas que no responden únicamente a las urgencias del presente y la mera supervivencia, sino que actualizan aprendizajes, improvisaciones y trayectorias del pasado, al mismo tiempo que ponen en juego imágenes de futuro y de vida buena,

Revista Memória em Rede, Pelotas, v.13, n.24, Jan/Jul.2021 - ISSN- 2177-4129 
valores morales y sentidos de dignidad que, en conjunto, otorgan profundidad temporal y valor situado a las prácticas económicas.

\title{
Como ha defendido Marc Augé
}

\begin{abstract}
Si bien es en efecto muy cierto que los seres humanos no viven día a día preocupados por sus fines últimos, no pueden contentarse indefinidamente con una blanda eternidad, con su tiempo detenido. Esto es cierto para los más desposeídos, como también para otros. Así la carrera por el sentido se emprende en las peores condiciones posibles. El sentido no es necesariamente el destino post mortem, la inmortalidad o el paraíso. Es la existencia del mañana (AUGÉ, 2015: 100)
\end{abstract}

En mi investigación, el seguimiento de las prácticas económicas para hacer posible la vida en la comunidad de El Boxo, fuese a partir de la observación directa o de los relatos de vida de los sujetos de investigación en torno a sus trayectorias laborales, me posibilitó establecer el engarce de las prácticas presentes con sus pasados. En este orden de ideas, y desde el punto de vista etnográfico, la observación y la descripción etnográfica de una situación implica asumir que, aunque entreguemos ciertos márgenes de posibilidad a lo espontáneo, una parte de ella se vincula con procesos que desde el pasado le configuran. En tal sentido, buscar el entendimiento de la situación y exponerla textualmente requiere superar el presente etnográfico asumiendo las tensiones de este con su pasado. Eric Wolf (2001: 24) reclamaba la necesidad de "ir más allá del presente etnográfico [...] para situar el objeto de nuestro estudio en el tiempo. No estamos tras los acontecimientos históricos", decía Wolf, "sino tras los procesos que apuntalan y moldean dichos sucesos".

Restituir la implicancia del pasado y la historia en situaciones presentes, implica asumir la capacidad de agencia de las personas para relacionarse con el tiempo y dar forma a sus futuros, precisamente porque aquello que observamos como pasado, o como resultado de éste, fue en algún tiempo el futuro de un presente hoy pretérito. Más radicalmente, ello se expresa en la idea koselleckiana, de profunda implicancia para la antropología, en torno a que "no existe ninguna historia que no haya sido construida mediante las experiencias y esperanzas de personas que actúan o sufren" (Koselleck, 1993: 335), por lo que el tiempo histórico no es otra cosa que la permanente tensión entre el campo de experiencias y el horizonte de expectativas (ibíd:: 340).

Aunque una parte de la teoría antropológica se ha mantenido siempre renuente a aceptar el peso del pasado y la historia (cf. BENSA, 2016), es justo asumir que en antropología "estamos acostumbrados a pensar en las muchas formas en que el pasado 
afecta al presente [...] Sin embargo, tendemos a estar menos acostumbrados a pensar en cómo los futuros imaginados y anticipados impactan en el presente" (MANKEKAR; GUPTA, 2017: 71). No obstante, del mismo modo en que el peso del pasado impide una lectura circunscrita al aquí y al ahora de la situación, lo hace el influjo de las imágenes de futuro sobre ésta. El futuro está implicado en el presente, tanto como el pasado, porque el presente es real sólo cuando se le considera - a manera de San Agustín- como un trecho en tensión entre dos inexistentes, pasado y futuro ${ }^{5}$.

Si el presente existe como trecho entre dos inexistentes, la preponderancia que tradicionalmente parte de la teoría antropológica ha otorgado al pasado como su configurador, debe ser puesta en un plano similar al influjo que sobre éste ejerce el futuro. Esta es la posición de gran parte de los abordajes antropológicos contemporáneos al tiempo porvenir. FelixRingel (2018) recuperando discusiones filosóficas sobre la metafísica del tiempo, de autores como Craig Bourne, ha defendido el ejercicio de una antropología presentista según la cual pasado y futuro son puestos en igualdad de condiciones ontológicas, porque ni el pasado ni el futuro existen en el presente, y ninguno está predeterminado.

Es claro que lo ya acontecido entrega certezas relativas, estabiliza ciertos modos de actuar, pensar y entender. Sin embargo, entre esas versiones estabilizadas de lo pretérito, existen otros muchos pasados que, a modo de Walter Benjamin, quedaron interrumpidos, truncados, que nunca han llegado a nuestros días. El presente de cada situación "reclama sus propios pasados relevantes" (VALENCIA, 2012:174) porque, al definir la realidad como proceso y, con ello, el presente como trozo de historia inacabada; entendemos dicho presente como un tiempo que está siendo configurado "desde su «de dónde», y por eso, como algo igualmente tendente, como algo hacia un «a dónde» todavía inconcluso" (Bloch, 2007: 43), sin un fin predeterminado y, por tanto, arena de disputa. En otras palabras, como defendió la antropóloga Carol Greenhouse (1996) en su ya clásico trabajo, tanto el tiempo como sus representaciones, son siempre situadas y emergen de las cambiantes y disputadas concepciones del orden social y la agencia. De este modo, lo presente en tanto que real es, acercándome a un lenguaje deleuziano, indisociable de lo

5 - “...si nada transcurriese, no habría tiempo pasado [...], si nada sobreviniese, no habría tiempo futuro [...] si nada existiese, no habría tiempo presente [...] El presente [...] si siempre existiese como presente y no pasase a pasado, ya no sería tiempo sino eternidad." (San Agustín; 2010: 560).

Revista Memória em Rede, Pelotas, v.13, n.24, Jan/Jul.2021 - ISSN- 2177-4129

periodicos.ufpel.edu.br/ojs2/index.php/Memoria 
virtual que éste actualiza. Lo real no aparece antes que lo posible sino que aparece como un conjunto de posibles simultáneos (cf. BODEI, 2014:25), porque la "posibilidad objetivareal rodea la realidad existente como un gran mar infinito con realizaciones posibles" (BLOCH, 2017: 86). Así, volviendo a la propuesta de Ringel (ibíd:: 9), debemos - a nivel teórico y metodológico- "tratar el pasado y el futuro de forma simétrica en el análisis antropológico, prestando una profunda atención a todas las relaciones y experiencias temporales".

Los abordajes antropológicos sobre el futuro, concuerdan en que la apertura de la disciplina a la temporalidad y en particular al tiempo porvenir, ofrece formas alternativas para ir más allá del presente etnográfico y para repensar los vínculos y los compromisos temporales que las personas implican en sus prácticas, restituyendo el influjo del tiempo futuro en el conjunto de modos de ser, estar y hacer que estudia la antropología. Como lo han expresado Bryant y Knight, (2019: 192-3):

\begin{abstract}
Si consideramos que la relación de la antropología con el presente, y por lo tanto con la temporalidad, es fundamental para la historia y el desarrollo de la disciplina, una nueva atención al futuro seguramente deletrea un nuevo tipo de antropología. Parece implicar una reorientación de la disciplina del estado del ser al proceso de convertirse, de la estructura a la agencia, y de las instituciones sociales a la esperanza, la planificación, las prácticas y la acción que proyectan a los que aún están por venir. En lugar de dar por sentado que tales instituciones durarán o deberían durar, esta nueva antropología pregunta acerca de las formas frágiles y tentativas en que se proyecta el presente en el futuro y éste último, en el presente y el pasado.
\end{abstract}

\title{
Sueños humildes
}

Desde el punto de vista etnográfico, y en particular en la etnografía que hacemos en las periferias de las periferias, más que confirmar o descartar las hipótesis teóricas sobre el fin o el adelgazamiento del futuro o aquellas que discurren en torno al presentismo ${ }^{6}$ que abundan en los tratamientos metropolitanos del futuro y la temporalidad, lo que tendríamos que observar, como se sugiere en la cita anterior,son "las formas frágiles y tentativas en que se proyecta el presente en el futuro y éste último, en el presente y el pasado" (ibídem.). Más aún, las etnografías sobre el futuro deberían llevarnos a concentrarnos en cuáles son las gramáticas particulares de esos futuros,

6 - Este uso de la noción de presentismo se refiere al elaborado en discusiones sobre la teoría y la filosofía de la historia por autores contemporáneos como Hartog (2007) y Gombrecht (2010) y que, en antropología, ha sido parcialmente trabajado por Marc Augé (cf. Augé, 1998; 2003; 2015).

Revista Memória em Rede, Pelotas, v.13, n.24, Jan/Jul.2021 - ISSN- 2177-4129

periodicos.ufpel.edu.br/ojs2/index.php/Memoria 
cómo se dicen y cómo se busca hacerles posible en prácticas presentes. Esto no quiere decir que los futuros que estudiamos en campo estén siempre en lineamiento o en conflicto abierto con los futuros enunciados desde arriba, pero tampoco quiere decir lo contrario. La apuesta es pensar los futuros de y desde abajo, los etnografiables desde el trabajo de campo, aquellos futuros que denomino sueños humildes.

Los sueños humildes, como nociones situadas de futuro, se nutren de horizontes diversos, heterogéneos, muchas veces incoherentes. Son futuros que comparten las características que asignó Gramsci a la noción de sentido común o la que otorgaron Gudeman y Rivera (1990) a la idea de conversación. Ambas se contraponen a la noción cerrada o sistémica que predomina en la mayoría de las definiciones antropológicas de cultura.

El sentido común, aquella "filosofía de los no filósofos" según Gramsci (cit. en CREHAN, 2002: 132)

no es algo rígido e inmóvil, sino que está en continua transformación, enriqueciéndose con ideas científicas y con las opiniones filosóficas que han penetrado en la vida cotidiana. El «sentido común» es el folklore de la filosofía, y siempre está a medio camino entre el folklore propiamente dicho y la filosofía, la ciencia y la economía de los especialistas. El sentido común crea el folklore del futuro, como una fase relativamente rígida de sabiduría popular en un momento y lugar determinados... no existe [por tanto] un único sentido común, porque [...éste] es un producto de la historia y parte de un devenir histórico.

Por lo tanto, ese sentido común, se sedimenta temporalmente por voces disímbolas, muchas veces contrapuestas, que intervienen en la construcción local del sentido. Estas intervenciones las podemos pensar bajo la noción de conversaciones, propuesto por Gudeman y Rivera (1990), en torno a las cuales se configuran "los modelos locales", para nuestro caso, los modelos o las ideas locales de futuro. Esas conversaciones locales, según los autores ocurren en el contexto de otras conversaciones dominantes, estructurales, generales. Desde la perspectiva de estos autores, lo que hay que investigar entonces son las articulaciones locales con esas conversaciones céntricas o dominantes, incluyendo acá las inscripciones del pasado y las prácticas del presente, entre el texto céntrico y las voces marginales. En tal sentido las conversaciones que configuran lo local están hechas del contacto y de lo que Appadurai (2001) ha definido como el trabajo de imaginación que construye lo local a partir de articulaciones diversas de modos de ser, hacer e imaginar la realidad. 
Si el futuro que se fue haciendo sentido común en el Valle del Mezquital fue el surgido desde una multiplicidad de voces y gramáticas particulares de decir el tiempo porvenir, para pensar en el cuándo y el cómo esta idea se estableció debemos recurrir a fuentes diversas que sin ser hegemónicas intervinieron en lo que la gente comenzó a imaginar como un porvenir mejor, cuando eso que los antropólogos estructuralistas denominaron futuro estructural $^{7}$, se quebró para siempre en la región o, por lo menos se transformó en uno más de los muchos futuros posibles en las trayectorias biográficas de los habitantes del Valle.

En antropología existe una larga tradición en el estudio de los sueños. Desde hace mucho, la antropología de lo onírico entre pueblos indígenas del mundo mostró que los sueños constituyen una forma específica de comunicación, conocimiento y orientación cultural, una manera de relacionarse con el mundo de lo existente y de lo trascendente, donde las fronteras entre lo real y lo fantástico suelen ser porosas. Sin embargo, poco ha dicho la antropología de los sueños diurnos. De esa capacidad de soñar despiertos que constituye ante todo una orientación temporal entre el ahora y el después, en que la imaginación parece dilatarse y el orden simbólico otorga cierto margen de libertad a una acción que busca reabrir el espacio de los posibles.

Al proponer una antropología de los sueños humildes, tributamos de las ideas del filósofo marxista ErnestBloch, en particular de su noción de sueños diurnos. Según este filósofo,

\begin{abstract}
La vida de los hombres se halla cruzada por sueños soñados despierto, una parte de dichos sueños es simplemente una fuga banal, también enervante, también presa para impostores; pero otra parte incita, no permite conformarse con lo malo existente, es decir, no permite la renuncia. Esta otra parte tiene en su núcleo la esperanza y es transmisible (BLOCH, 2007: 26).
\end{abstract}

Esto sueños diurnos según Bloch motivan el "traspasar", la capacidad humana de alejarse de una vida pasiva, de una actitud meramente contemplativa de la realidad presente, para tomar parte activa en la transformación de esa realidad, de cara a lo que se imagina como porvenir. Ese traspasar para el filósofo, no está

7 - La noción de futuro estructural fue propuesta por Evans Pritchard (1977:122), en su análisis del tiempo entre los Nuer. Para el autor en esta sociedad tradicional; el tiempo, como tiempo estructural, aparece como reflejo de una estructura social permanente, dentro de la cual "el futuro estructural de un hombre está ya fijado y ordenado en periodos diferentes, de modo que se puede prever los cambios totales de estado que experimentará un muchacho en su paso previsto a través del sistema social".

Revista Memória em Rede, Pelotas, v.13, n.24, Jan/Jul.2021 - ISSN- 2177-4129

periodicos.ufpel.edu.br/ojs2/index.php/Memoria 
dirigido al mero espacio vacío de un algo ante nosotros, llevado sólo por la fantasía, figurándose las cosas sólo de modo abstracto. Al contrario: concibe lo nuevo como algo procurado en el movimiento de lo existente, si bien, para poder ser puesto al descubierto, exige de la manera más intensa la voluntad dirigida a este algo [...] En sentido primario, el hombre que aspira a algo vive hacia el futuro; el pasado sólo viene después; y el auténtico presente casi todavía no existe en absoluto (ibíd: 26-7)

De ahí que podamos entender los sueños humildes como aquel modelo local de futuro imaginado, emergente de las conversaciones diversas e históricamente situadas que construyen el sentido común y que posibilitan a las personas imaginar otras vidas posibles y comprometerse con ellas desde el punto de vista de las prácticas presentes.

Lo que quiero hacer notar es que las prácticas que observamos en campo, poseen una densidad temporal que, lo mismo que informan de elementos del pasado, de la tradición y de los habitus; pueden darnos cuenta de la reflexividad y de la capacidad de las personas para actuar en el mundo presente de cara a la transformación de las circunstancias. Las prácticas pueden dar cuenta de los compromisos más íntimos que las personas adquieren con las imágenes de futuro, con sus sueños y esperanzas. Cuando de ganarse y hacer posible la vida se trata, el futuro abrazado bajo nociones situadas de vida buena se presentifica en la práctica y no solo en los discursos, porque esas nociones están, parafraseando a Jonh Berger (2016: 12), tatuadas en la imaginación, punto por punto, con una aguja de añoranza.

En tal sentido, el compromiso que las personas establecen con sus sueños y con las imágenes de futuro que les enmarcan, es propiciado por modos de esperanza representacional, referidas a aquellas esperanzas que se dirigen hacia un futuro específico y esperado (COOK; CUERVO, 2019). Estas esperanzas son las que permiten articular una trama entre el pasado y presente de esfuerzo y lo que se piensa como recompensa de dicho esfuerzo. En el caso de los trabajadores de El Boxo, la construcción de una casa, la mejora de la comunidad o, en años recientes, el retorno migratorio; configuran esperanzas representacionales que ayudan a hilvanar imaginariamente el tiempo ahora con su porvenir. Lograr avances en parte de esos sueños humildes, comenzar o continuar edificando la vivienda, por ejemplo, provee al presente de fragmentos concretizados de esperanzas representacionales que continúan otorgando sentidos a los esfuerzos presentes y activando representaciones afirmativas del futuro. 
Los sueños humildes emergen también de la capacidad reflexiva de las personas ante la evaluación de sus circunstancias. Sigo en este punto a la socióloga Margaret Archer y su noción de reflexividad y conversación interna, entendida como el proceso reflexivo que despliegan las personas (agentes en el lenguaje de la autora) entre sus preocupaciones y la elaboración de proyectos frente a dichas preocupaciones ${ }^{8}$. Las conversaciones internas abarcan, según Archer (2007:2), "un amplio terreno que, en lenguaje sencillo, puede extenderse desde el soñar despierto, el fantasear y la vituperación interna; a través de ensayos [imaginativos] para un próximo encuentro, reviviendo [imaginariamente] eventos pasados [o] planeando eventualidades futuras".

Esas conversaciones internas son fundamentales para pensar las respuestas que las personas dan ante las restricciones o las habilitaciones que las estructuras sociales y socioculturales les presentan para su acción ${ }^{9}$. Pero son al mismo tiempo, fundamentales en la reevaluación de los contextos cambiantes en que los proyectos son reformados, reelaborados, reconsiderados o modificados por otros nuevos. La capacidad de improvisar y responder de manera espontánea ante circunstancias cambiantes aportan en el mantenimiento de la trama temporal que articula los presentes de esfuerzo a los futuros imaginados ${ }^{10}$. Ello es, por ejemplo, lo que observo en el paso de la migración temporal campo-ciudad, a la migración internacional de los trabajadores de El Boxo; cuando los repertorios para ganarse la vida, vía la movilidad a ciudad de México fueron bloqueadas por las crisis mexicanas de finales de siglo XX.

A la hora de intentar intervenir ante sus circunstancias, los

8 - "Nadie puede tener una preocupación última y dejar de hacer algo al respecto. En su lugar, cada persona busca desarrollar un curso de acción concreto para darse cuenta de esa preocupación mediante la elaboraciónde un "proyecto", [...] La acción en sí depende de la existencia de lo que se denomina "proyectos", donde un proyecto representa cualquier curso de acción comprometido intencionalmente [...] La respuesta a por qué actuamos es para promover nuestras preocupaciones; formamos "proyectos" para avanzar o para proteger lo que más nos importa. Si los proyectos fueran opcionales, en el fuerte sentido de que las personas podrían vivir sin ellos, lo social sería como el mundo natural, gobernado solo por las leyes de la naturaleza. Los seres humanos se distinguen no como portadores de proyectos, [...] sino debido a su capacidad reflexiva para diseñar (y rediseñar) muchos de los proyectos que persiguen (Archer, 2007: 7).

9 - "Debido a que la respuesta del agente a una restricción (o habilitación) es una cuestión de deliberación reflexiva, puede adoptar formas muy diferentes: desde el cumplimiento a través de la evasión y la acción estratégica hasta la subversión. Lo único que rara vez se encuentra, si es que alguna vez se encuentra, es una completa uniformidad de respuesta en nombre de cada agente que encuentra la misma restricción o la misma habilitación" (ibid., 2017:155).

10 - Las dinámicas temporales de la improvisación han sido estudiadas en antropología por Hallam y Tim Ingold (2007), mientras que las ligadas a la espontaneidad y su vínculo con el tiempo futuro han sido desarrolladas por Roxana Moroşanu (2016).

Revista Memória em Rede, Pelotas, v.13, n.24, Jan/Jul.2021 - ISSN- 2177-4129 periodicos.ufpel.edu.br/ojs2/index.php/Memoria 
resultados varían enormemente según la creatividad de los agentes para idear respuestas nuevas, incluso a situaciones que pueden haber ocurrido muchas veces antes. En última instancia, el resultado exacto varía según las preocupaciones personales y los grados de compromiso de los agentes, así como con los costos que los diferentes agentes pagarán para llevar a cabo sus proyectos frente a obstáculos y limitaciones estructurales (ARCHER, 2017: 155).

Los sueños diurnos y los compromisos con esos sueños, son etnografiables porque se expresan en acciones concretas o, como diría Paula Godinho (2017), en prácticas posibles que las personas despliegan en el presente de cara al porvenir. El estudio de esos sueños, que como aportó Bloch: tienen en su núcleo la esperanza y son transmisibles, posibilitan el establecimiento de una trama temporal a partir de las cuales las propias personas cuentan parte de sus historias y las de sus comunidades, establecen los marcadores discursivos entre los antes y los después, y vinculan el pasado a procesos en curso que no terminan de resolverse.

En muchos casos, la promesa que adelantan esos sueños no puede situarse con facilidad sólo en una parcialidad del tiempo, porque afectan - como nos sugiere Berger en el epígrafe de este artículo-, de manera simultánea al pasado, al presente y al futuro. Por ello, sostener esos sueños humildes ante situaciones de absoluta incertidumbre, como la que experimentan los actuales migrantes internacionales de El Boxo en Estados Unidos, es aferrarse a una certeza, la certeza de que, como me dijera uno de mis colaboradores "acá [en la comunidad] está el futuro, allá [a Estados Unidos] nada más se va a trabajar." Para estos migrantes, seguir apostando a esos sueños humildes es propiciar pertenencias para el futuro retorno y para continuar atando el presente de esfuerzo al porvenir imaginado, mediante prácticas constantes y pequeños fragmentos de esperanza que prefiguran esos futuros imaginados.

\section{Consideraciones finales}

En el marco de la búsqueda del bienestar y la vida buena, el compromiso manifiesto en el trabajo presente - para los trabajadores de El Boxo, en el andar trabajando lejos para hacer posible la vida de los suyos en la comunidad-, hunde su temporalidad en los pasados que comenzaron a dar forma a esas prácticas para ganarse la vida y a los 
aprendizajes temporales para gestionar las ausencias. Los primeros trabajadores que salieron de El Boxo tras un salario y volvieron a la comunidad con nuevos estilos de vida, aspiraciones y modelos de vida buena, no sólo desestabilizaron la norma de conducta económica previa y con ello quebraron para siempre el futuro estructural que para los jóvenes se presumía en el marco de una sociedad tradicional; sino que, además, iniciaron directa o tangencialmente la secuencia de transformaciones sobre las que se pueden establecer los contrastes entre la sociedad otomí del Valle del Mezquital del siglo pasado y la sociedad otomí contemporánea.

Esas generaciones, las que despertaron "un nuevo espíritu de elevación material" en el Mezquital (GUERRERO, 1983: 219), fueron las que propiciaron descripciones etnográficas tales como: “...en el Valle del Mezquital se respira un despertar general, una nueva actitud de aceptación del cambio" (COPEVI, 1970a: 32). Con estas nuevas generaciones, el atávico indígena otomí, parecía dar paso a un nuevo sujeto comprometido con el futuro propio y con el de sus comunidades.

\footnotetext{
Es impresionante ver a los hombres arraigados en sitios miserables, dispuestos a enfrentar las tareas más arduas para levantar sus comunidades [...] Tras siglos de letargo ven una luz de esperanza y se ciñen a ella con verdadera pasión. Son estos los nuevos hombres del Valle del Mezquital, su futuro, su esperanza misma (COPEVI, 1970a: 32-3)
}

Sin entender esa pasión con la que los hombres y mujeres de antaño abrazaron la esperanza por un futuro mejor, sería imposible comprender las maneras en que hoy se hace posible el mantenimiento de los vínculos familiares y comunitarios a distancias espaciales y temporales enormes, acrecentadas y radicalizadas por las actuales condiciones de la migración indocumentada en Estados Unidos, que hacen del tiempo del proyecto migratorio de los mezquitalenses y su resolución, un tiempo incierto. Del mismo modo que, sin considerar los sueños humildes de los migrantes contemporáneos, como aquel que prefigura el futuro retorno a su comunidad de origen, sería imposible entender los compromisos de los que andan lejos por seguir perteneciendo y favoreciendo dinámicas para pertenecer desde lejos.

Como ha apuntado Fischer (2014.: 2), si el bienestar es algo más que bien, "tal vez la buena vida no sea un estado que se obtendrá [...sino] una aspiración continua por algo mejor que da sentido a las actividades de la vida". Creer en un futuro mejor no es sino invocar a una creencia y sobre los sistemas de creencias y su impacto en las prácticas 
concretas la antropología ha dicho mucho. Al ser integradas entre los activos con los que cuenta la gente, en los que cree y con los que se identifica; las imágenes de vida buena son incorporadas al orden simbólico, "capaz de manipular las expectativas y las esperanzas, mediante una exposición performativa más o menos inspirada y exaltadora del porvenir" (BOURDIEU, 1999: 310). De este modo el presente de lo múltiple se satura de situaciones en que las prácticas son movilizadas por la creencia en un futuro diferente, deseable e imaginado como posible. Como ha dicho Jacques Rancière (2013: 73), "las creencias no afectan las vidas sino a través de las situaciones. Y las situaciones sí son siempre reales. Están talladas en la misma madera de la existencia material, en la duración de las inercias, de las esperas y de las creencias".

“Jamás observo", decía el antropólogo Jean Bazin (2017: 121), "otra cosa que situaciones". La "situación", continuaba, "es una configuración singular, por definición temporal, el momento actual de una historia en curso". En las situaciones, que observamos y describimos etnográficamente se expresa aquella conexión entre las prácticas del presente y las imágenes de futuro y vida buena, la que ha permitido vivir los ahora de urgencias y esperas, el impase de vivir en el momento avasallantemente presente en una comunidad donde la movilidad se hizo habitus e imperativo para la reproducción social. Es precisamente en esa conexión de instantes, situaciones y fragmentos de esperanzas, en la que reposa la duración de la comunidad de El Boxo y sobre la cual se afirman pertenencias, se arraigan proyecciones y asignan valores y sentidos al presente.

Estudiar la creencia en el tiempo porvenir y el compromiso, manifiesto en prácticas concretas, que las personas adquieren con las imágenes que desde ese tiempo se proyectan al presente, implica que al describir una situación presente "describimos un conjunto de relaciones con el pasado y el futuro" (BENSA, 2016: 103); un conjunto de ideas y relatos que se actualizan, de acciones que reclaman su sentido del pasado y que se despliegan para alcanzar tal o cual estado en el futuro. Así entendido, el tiempo de la etnografía, aquello que tradicionalmente se ha definido como presente etnográfico, es sólo formalmente presente.

Podemos construir una antropología del futuro donde las palabras y los sueños humildes de los habitantes de El Boxo, sean un ejemplo más de las formas diversas de humanidad con los que los antropólogos hemos llenado las bibliotecas. Pero escuchar con atención puede ayudarnos también a imaginar una antropología que, en esas 
palabras, no solo descubra humanidad diversa, sino que también se acerque a formas de humanidad futura, trazada por sueños humildes, por deseos de pertenencia y por compromisos con el presente y el porvenir de los cercanos. Una antropología del futuro distante de la prospectiva de escenarios probables, encerrados en la configuración de un presente de explotación y degradación. No se trata, desde luego, de anteponer voluntariosamente una antropología luminosa y propositiva, ante una antropología de lo oscuro (cf. ORTNER, 2016), como si el miedo y la esperanza no fueran siempre las modulaciones afectivas que acompañan cualquier pensamiento de futuro. Por el contrario, se trata de observar y escuchar en esas formas de humanidad diversas, futuros igualmente diversos que aporten a la construcción de una antropología de lo posible, de otros mundos posibles, atenta de la esperanza y de la humildad de aquellos que, tal y como lo están haciendo los habitantes de El Boxo, intentan construir día a día sus futuros a mano.

\section{Bibliografía}

Adam, Barbara y Chris Groves. . Future Matters: Action, Knowledge, Ethics. Leiden: Brill, 2007.

AGIER, Michel. .Zonas de frontera: la antropología frente a la trampa identitaria. Rosario: Editorial de la Universidad Nacional de Rosario, 2015.

APPADURAI, Arjun. La modernidad desbordada. Dimensiones culturales de la globalización. Buenos Aires: Ediciones TRILCE, FCE, 2001.

APPADURAI, Arjun. El futuro como hecho cultural. Ensayos sobre la condición global. Buenos Aires: FCE, 2015.

ARCHER, Margaret. . Making our way through the World. London: Cambridge University Press, 2007.

ARCHER, Margaret. The ontological status of subjectivity: the missing link between structure and agency. En: Tom Brock, Mark Carrigan y Graham Scambler (edrs.) Structure, Culture and Agency Selected Papers of Margaret Archer. New York: Routledge, 2017.

AUGÉ, Marc. Hacia una antropología de los mundos contemporáneos. Barcelona: Gedisa, 1998.

AUGÉ, Marc. El tiempo en ruinas. Barcelona: Gediasa, 2003.

AUGÉ, Marc. ¿Qué paso con la confianza en el futuro? Buenos Aires: Siglo XXI, 2015.

Revista Memória em Rede, Pelotas, v.13, n.24, Jan/Jul.2021 - ISSN- 2177-4129

periodicos.ufpel.edu.br/ojs2/index.php/Memoria 
BAZIN, Jean. . "Interpretar o describir. Notas críticas sobre el conocimiento antropológico." En: Mariana Garzón (editora), Historia pragmática: un perspectiva sobre la acción, el contexto y las fuentes. Buenos Aires: Prometeolibros, 2017.

BENNETT, Julia. Doing belonging: A sociological study of belonging in place as the outcome of social practices. PhD Thesis, University of Manchester, UK, 2012.

BENSA, Alban. El fin del exotismo: ensayos de antropología crítica. Zamora, Michoacán: El Colegio de Michoacán, 2016.

BERGER, Jonh. "Prólogo." En: Timothy O'Grady, Sabía leer el cielo. La Rioja, España: Pepitas de calabaza, 2016.

BERLANT, Lauren. Optimismo cruel. En: Debate Feminista. Vol. 45 Issue 23, pp. 107135, 2012.

BLOCH, Ernest. .El principio esperanza. Vol. I. Madrid: Trotta, 2007.

BLOCH, Ernest. ¿ ¿Despedida de la utopía? Madrid: Machado Libros, 2017.

BODEI, Remo. Imaginar otras vidas: Realidades, proyectos y deseos. Barcelona: Herder, 2014.

BOURDIEU, Pierre. Meditaciones pascalianas. Barcelona: Anagrama,1999.

BRYANT, Rebecca y Knight, Daniel. The Anthropology of the Future. Cambridge: Cambridge UniversityPress, 2019.

CANDAU, Jöel. Antropología de la memoria. Buenos Aires: Nueva Visión, 2002.

CARTON, Hubert. Formas de explotación de los asalariados agrícolas en una zona de mediano desarrollo capitalista. México: Macehual, 1982.

CONTRERAS, Raúl. Imaginar futuros. La temporalidad del ganarse la vida en el Valle del Mezquital, Hidalgo; México. Tesis para optar al grado de doctor. Posgrado en Antropología, Universidad Nacional Autónoma de México, 2019.

CONTRERAS,, Raúl. Imaginar un futuro (de) concreto. El cemento y las formas de habitar en el Valle del Mezquital. En: Hernán Salas (coord.) "Etnografías contemporáneas del poder: formas de dominación en el mundo rural”. México: IIA-UNAM, pp. 233-66, 2019a.

CONTRERAS,,Raúl.La música de Lupita. Esbozos para una antropología de lo contemporáneo en una comunidad rural mexicana. Revista de El Colegio de San Luis, $\mathrm{N}^{\circ} 20$, pp. 325-43, 2019b.

COOK, Julia y Hernán Cuervo. Agency, futurity and representation: Conceptualising hope in recent sociological work. TheSociologicalReview1-16, pp. 1-15, 2019.

COPEVI. Investigación zonal en el Valle del Mezquital. Vol. I. Valle del Mezquital: problemática y cambio. México: COPEVI, 1970.

COPEVI. (1970a). Investigación zonal en el Valle del Mezquital. Vol. IV. Valle del Mezquital: Aspectos de la realidad socio-cultural. México: COPEVI. 
CREHAN, Kate. Gramsci, cultura y antropología. Barcelona: Bellaterra, 2004.

EAGLETON, Terry. Esperanza sin optimismo. Barcelona: Taurus, 2016.

EVANS-PRITCHARD, Edward. Los Nuer. Barcelona: Anagram, 1977.

FISCHER, Edward. The Good Life: Aspiration, Dignity, and the Anthropology of Wellbeing. Stanford, California: Stanford UniversityPress, 2014.

GALINIER, Jacques. Pueblos de la Sierra madre: Etnografía de la comunidad otomí. Nueva edición. México: Centro de estudios mexicanos y centroamericanos, 1977.

GAMIO, Manuel. "Consideraciones sobre el problema del Valle del Mezquital." En: Américalndígena, 12, Mayo, 1952.

GARDINER, Pauline y Winnie Lem. "Migration, Temporality and Capitalism: A brief Introduction." En: Pauline Gardiner y Winnie Lem (editors), Migration, Temporality, and Capitalism: Entangled mobilities across global spaces. Switzerland: PalgraveMacmillan, 2018.

GIDDENS, Anthony Modernidad e identidad del yo. El yo y la sociedad en la época contemporánea. Barcelona: Península, 1997.

GODINHO, Paula. O futuro é para sempre. Experiência, expectativa e práticaspossíveis. Lisboa: Letra Livre /Através Editora, 2017.

GREENHOUSE, Carol. A Moment's Notice. Time Politics across Cultures. New York: Cornell University Press, 1996.

GUDEMAN, Stephen y Alberto Rivera. Conversations in Colombia: The Domestic Economy in Life and Text. Cambridge: Cambridge University Press,1991.

GUMBRETCH, Hans Ulrich. Lento presente. Sintomatología del nuevo tiempo histórico. Madrid: Escolar y Mayo editores, 2010.

HALLAM, Elizabeth y INGOLD, Tim. "Creativity and Cultural Improvisation: An Introduction." En: Elizabeth Hallam y Tim Ingold (edited) Creativity and Cultural Improvisation. Oxford: BergPublishers, 2007.

HARTOG, François. Regímenes de historicidad: presentismo y experiencias del tiempo. México: Universidad Iberoamericana, 2007.

JACKSON, Michael. Life within limits: Well-being in a World of Want. Durham, N.C.: Duke University Press, 2011.

KOSELLECK, Reinhart. Futuropasado. Para una semántica de los tiempos históricos. Barcelona: Paidós, 1993.

LYNCH, Paul. "Composition's New Thing: Bruno Latour and the Apocalyptic Turn." En: College English 74, no. 5: 758-76, 2012.

MANKEKAR, Purnima y GUPTA, Akhil. "Future tense: Capital, labor, and technology in a service industry (The 2017 Lewis Henry Morgan Lecture)". En: HAU: Journal of Ethnographic Theory, 7:3, 67-87, 2017. 
MAY, Vanessa. "Belonging across the lifetime: Time and self in Mass Observation accounts." En: The British Journal of Sociology, 69(2), 306-322, 2017.

MAY, Vanessa. "Belonging from afar: nostalgia, time and memory." En: TheSociologicalReview, 65(2), 401-415, 2017a.

MEDINA, Andrés y QUEZADA, Noemi. Panorama de las Artesanías Otomíes del Valle del Mezquital. México: UNAM, Instituto de InvestigacionesAntropológicas, 1975.

MILAR, Kathleen. Reclaiming the Discarded: Life and Labor on Rio's Garbage Dump. Durham, Duke University Press, 2018.

MOROşANU, Roxana. An Ethnography of Household Energy Demand in the UK. Everyday Temporalities of Digital Media Usage. Londres: Palgrave Macmillan, 2016.

NAROTZKY, Susana y BESNIER, Niko. "Crisis, Value, and Hope: Rethinking the Economy." Introduction to Supplement 9: Current Anthropology, Vol. 55, No. S9, Crisis, Value, and Hope: Rethinking the Economy: S4-S16, 2014.

NOLASCO, Margarita. "Los otomíes. Análisis de un grupo marginal." En: Anales del Museo Nacional de México. Sexta época, Vol. 15. Pp. 153-185, 1963.

ORTNER, Sherry. "Dark anthropology and its others: Theory since the eighties." En: HAU: Journal of Ethnographic Theory 6:1, 47-73, 2016.

PADELFORD, Víctor. "Otomi hause types as a reflection of acculturation". En: H. Russell, Los Otomies. Paper from the Ixmiquilpan field school. Washington: Pullman,1969.

PALLASMAA, Juhani. Habitar. Barcelona: Gustavo Gili, 2016.

PINE, Frances. "Migration as Hope: Space, Time and Imagining the Future." En: Current Anthropology, 55(9), pp. 95-104, 2014.

RAMSAY, Richard. Gundhó: An Ethnographic Study of an Otomí Community, doctoral dissertation, University of North Carolina, 1974.

RANCIĖRA, Jacques. BelaTarr. Después del final. Buenos Aires: El cuenco de plata, 2013.

REDFIELD, Robert. .El mundo primitivo y sus transformaciones. México: FCE, [1953] 1963.

RINGEL, Felix. Back to the Postindustrial Future: An Ethnography of Germany's FastestShrinking City. Oxford: Berghahn, 2018.

SAN AGUSTíN. Confesiones. Madrid: Editorial Gredos, 2010.

SCHMIDT, Ella. "Ciudadanía comunal y patrimonio cultural indígena: el caso del Valle del Mezquital, Hidalgo." En: DimensiónAntropológica, vol. 59, septiembre-diciembre, pp. 147162, 2013.

SEN, Amartya. "Rational fools: A critique of the behavioral foundations of economic theory." En: Philosophy and public affairs, 6 (4), 317-344, 1977. 
SEN, Amartya. "Rational fools: A critique of the behavioral foundations of economic theory." En: Philosophy and publicaffairs, 6 (4), 317-344, 1977.

TRANFO. Luigi. Vida y Magia en un pueblo otomí del Mezquital. México: Instituto Nacional Indigenista, 1990[1970].

VALENCIA, Guadalupe y CONTRERAS, Raúl. "El futuro como esperanza." En: Coordenadas 2050, Cuadernos de la Coordinación de Humanidades, Universidad Nacional Autónoma de México \#37, 2018.

VALENCIA, Guadalupe. "La contemporaneidad interrogada." En: J. Gandarilla, R. Ramos, y G. Valencia (coords.) Contemporaneidad(es). Madrid: Sequitur, 2012.

WALLMAN, Sandra. "Introduction: contemporary futures." En: Sandra Wallman (ed.), Contemporary futures: perspectives from social anthropology, pp. 1-20. London: Routledge, 1992.

WOLFf, Eric. Figurar el poder: ideologías de dominación y crisis. México: CIESAS, 2001.

ŽlŽEK, Slavoj. Viviendo al final de los tiempos. Madrid: AKAL, 2012. 